\title{
Celulitis sinérgica necrotizante como complicación de la recidiva de un carcinoma de vejiga de alto grado en paciente cistectomizado
}

\author{
Benítez Morillo MJ, Moro Sánchez ML, Tejada Ruiz FJ. \\ Servicio de Medicina Intensiva. Hospital de Mérida. Mérida.
}

Actas Urol Esp. 2007;31(2):172-173

\section{Sr. Director:}

Tras la atenta lectura de la nota clínica "Desderivación urinaria; de Bricker a Studer. A propósito de dos casos" aportada por Cabello et al. en Actas urológicas españolas (2006;30:939942) nos gustaría manifestarle que el desarrollo de técnicas quirúrgicas en beneficio de una mayor calidad de vida para el paciente nos parece un esfuerzo loable y digno de admiración.

En relación al tema quisiéramos aportar una caso que ilustra una complicación grave en un paciente de 69 años con un carcinoma epidermoide de vejiga de alto grado en estadio III (T3b NO MO) a quien se realizo una cistectomía radical con derivación urinaria heterotópica ileal según la técnica de Bricker-Wallace tipo II con posterior tratamiento con quimioterapia. Cinco meses después ingresó en nuestra unidad por un cuadro de shock séptico y fracaso multiorgánico, (respiratorio, renal, hematológico y neurológico) que precisó de soporte vital avanzado, ventilación mecánica y drogas vasoactivas. Un mes antes había sido estudiado en régimen de ingreso hospitalario por cuadro febril sin foco aparente y un aumento de tamaño en el muslo izquierdo destacando en la exploración adenopatías inguinales que fueron analizadas mediante PAAF, cuyo resultado no fue concluyente aunque se descarto malignidad. Tras el estudio se diagnosticó de trombosis venosa profunda al haberse detectado mediante eco-doppler la trombosis de la vena femoral común siendo alta a su domicilio con tratamiento anticoagulante.

Al ingreso en la unidad destacaba en la exploración física un extenso enfisema subcutáneo en hemicuerpo izquierdo, que abarcaba desde la rodilla hasta la axila extendiéndose por el brazo hasta codo y afectando de forma parcheada al hemitórax derecho. Se realizo TAC toraco-abdo- minal (Fig. 1) donde se apreciaba gran enfisema subcutáneo de todo el hemicuerpo izquierdo, absceso en psoas iliaco izquierdo asociado a colección hipodensa con aire extendida a través de canal inguinal al muslo izquierdo, liquido libre en fosa iliaca izquierda y derrame pleural izquierdo. Intervenido quirúrgicamente se encontró gran masa adherida a sigma que impedía su movilización y resección con plastrones inflamatorios y que en la anatomía patología se diagnostico como recidiva de carcinoma epidermoide vesical. El paciente falleció en UCI tras haber sido sometido a fasciectomías y amplia desbridación al hallarse afectación extensísima de piel, tejido celular subcutáneo, fascias y músculo compatibles con celulitis sinérgica necrotizante El resultado microbiológico de las muestras obtenidas durante la cirugía fue el crecimiento de Enterococcus faecalis (grupo D), Escherichia coli, Streptococcus grupo viridans y Bacteroides fragilis.

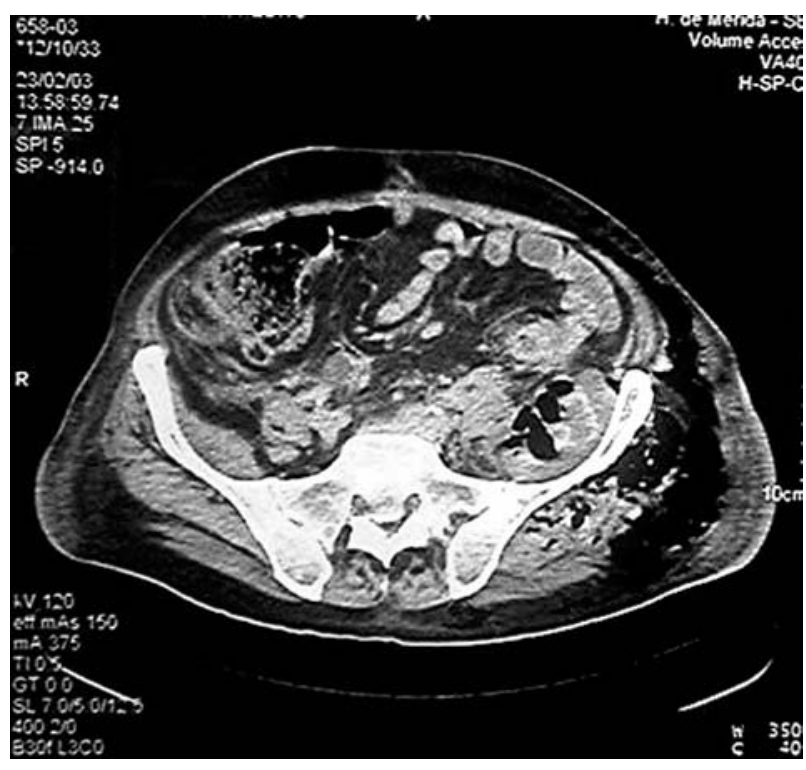

FIGURA 1 
Es excepcional que un absceso de psoas constituya la presentación inicial de una perforación colónica secundaria a la recidiva de un tumor vesical. De forma muy excepcional se han descrito abscesos de psoas secundarios a neoplasias de colon $^{1-4}$, siendo aun menos frecuentes casos de perforación secundaria a recidivas de tumores de otros órganos. El diagnóstico preoperatorio puede resultar difícil debido a una presentación clínica que puede llegar a ser muy atípica y en ocasiones sólo se logra establecer mediante cirugía. Ante la presencia de gas en el interior del absceso en el TAC deberíamos sospechar el origen intestinal del mismo ${ }^{5}$.

La celulitis sinérgica necrotizante es una variante de la fascitis necrotizante que afecta piel, tejido celular subcutáneo, fascias y músculo causando necrosis tisular y severa toxicidad sistémica de forma rápidamente progresiva El cultivo de los tejidos afectados muestra el crecimiento de especies anaerobias (bacteroides , peptoestreptoccoco) junto con especies anaerobias facultativas (estreptococos diferentes al grupo A) y enterobacterias Son decisivos para mejorar el pronostico una alto índice de sospecha y un tratamiento agresivo que debe incluir una resucitación enérgica en la unidad de Medicina Intensiva, antibioterapia de amplio espectro y una intervención quirúrgica precoz y muy agresiva, a pesar de lo cual persiste una alta mortalidad ${ }^{6}$.
El caso que nos ocupa ilustra una rara complicación de un carcinoma vesical, cuya recidiva una vez extirpado originó una lesión en colon que dio lugar a una infección de evolución subaguda ( no diagnosticada) con formación de un absceso en psoas que desembocó en una celulitis sinérgica necrotizante de desarrollo rápido y fatal.

\section{REFERENCIAS}

1. Mann GN, Scoggins CR, Adkins B. Perforated Cecal Adenocarcinoma presenting as a thigh ascess. South Med J. 1997;90(9):949-951

2. Peterson CM, Allison JG, Lu CC. Psoas abscess resulting from perforating carcinoma of the sigmoid colon. Report of a case. Dis Colon Rectum. 1983;26(6):390-392.

3. Insua Vilarino SA, Sanchez Leira J, Marino Rozados A, Garcia Figueiras R. Psoas abscess secondary to colonic neoplasm. Rev Esp Enf Digest. 1995;87(11):830-831.

4. Tabet J, Targarona EM, Moreno A, Trias M. Absceso de psoas como primera manifestación de un tumor apendicular. Med Clin (Barc). 1996;106(14):556-557.

5. Merino D, Perez J M., Creagh R et al. Absceso de psoas como primera manifestación de un adenocarcinoma de sigma. An. Med. Interna (Madrid), set. 2001, vol.18, no.9, p.56-57. ISSN 0212-7199.

6. File TM. Necrotizing Soft Tissue Infections. Curr Infect Dis Rep. 2003;5(5):407-415.

Correspondencia autor: Dr. M.F. Benitez Morillo. Servicio de Medicina Intensiva. Hospital de Mérida. Polígono Nueva Ciudad s/n. 06800 Mérida. Tel.: 924381000 Correo electrónico autor: miguelbenitezmorillo@ya.com Información artículo: Cartas al Director

Trabajo recibido: noviembre 2006

Trabajo aceptado: diciembre 2006 